\title{
The Role of O-GlcNAcylation for Protection against Ischemia-Reperfusion Injury
}

\author{
Rebekka Vibjerg Jensen $1, *\left(\mathbb{D}\right.$, Ioanna Andreadou ${ }^{2}$, Derek J. Hausenloy $3,4,5,6,7,8$ and \\ Hans Erik Botker ${ }^{1}[$ \\ 1 Department of Cardiology, Aarhus University Hospital, Skejby, Palle Juul-Jensens Blvd. 99, \\ 8200 Aarhus N, Denmark; heb@dadlnet.dk \\ 2 Laboratory of Pharmacology, Faculty of Pharmacy, National and Kapodistrian University of Athens \\ Panepistimiopolis, 15771 Zografou, Greece; jandread@pharm.uoa.gr \\ 3 Cardiovascular \& Metabolic Disorders Program, Duke-National University of Singapore Medical School, \\ Singapore 169857, Singapore; derek.hausenloy@duke-nus.edu.sg \\ 4 National Heart Research Institute Singapore, National Heart Centre, Singapore 169609, Singapore \\ 5 Yong Loo Lin School of Medicine, National University Singapore, Singapore 119228, Singapore \\ 6 The Hatter Cardiovascular Institute, University College London, London WC1E 6HX, UK \\ 7 The National Institute of Health Research University College London Hospitals Biomedical Research Centre, \\ Research \& Development, London W1T 7DN, UK \\ 8 Tecnologico de Monterrey, Centro de Biotecnologia-FEMSA, Monterrey 64849, Mexico \\ * Correspondence: rebekka.vibjerg@clin.au.dk; Tel.: +45-3071-4316
}

Received: 30 November 2018; Accepted: 15 January 2019; Published: 18 January 2019

check for updates

\begin{abstract}
Ischemia reperfusion injury (IR injury) associated with ischemic heart disease contributes significantly to morbidity and mortality. O-linked $\beta$-N-acetylglucosamine (O-GlcNAc) is a dynamic posttranslational modification that plays an important role in numerous biological processes, both in normal cell functions and disease. O-GlcNAc increases in response to stress. This increase mediates stress tolerance and cell survival, and is protective. Increasing O-GlcNAc is protective against IR injury. Experimental cellular and animal models, and also human studies, have demonstrated that protection against IR injury by ischemic preconditioning, and the more clinically applicable remote ischemic preconditioning, is associated with increases in O-GlcNAc levels. In this review we discuss how the principal mechanisms underlying tissue protection against IR injury and the associated immediate elevation of O-GlcNAc may involve attenuation of calcium overload, attenuation of mitochondrial permeability transition pore opening, reduction of endoplasmic reticulum stress, modification of inflammatory and heat shock responses, and interference with established cardioprotective pathways. O-GlcNAcylation seems to be an inherent adaptive cytoprotective response to IR injury that is activated by mechanical conditioning strategies.
\end{abstract}

Keywords: ischemia-reperfusion injury; O-GlcNAc; cardioprotection

\section{Introduction}

Stressors triggering organ damage and disease continuously influence the cells of biological organisms. Damage introduced by ischemia reperfusion injury (IR injury) is pivotal in diseases such as coronary heart disease (CHD) and stroke, causing substantial mortality and morbidity [1,2]. Restoration of blood flow to the ischemic area is the most important component for reduction of infarct size. Implementation of reperfusion modalities, including percutaneous coronary intervention and thrombolytic therapy, has significantly improved mortality and morbidity over the last 20 years [3,4]. However, CHD remains the leading cause of death in the Western world [5]. While reperfusion is essential for cytoprotection, it also contributes to cellular damage by inducing reperfusion injury [6]. 
The body has innate cytoprotective systems that activate protection against IR injury. Ischemic preconditioning (IPC) is a potential treatment modality that activates intrinsic protective mechanisms against IR injury. By short sublethal periods of ischemia and reperfusion, IPC activates a variety of protective mechanisms that render tissue or organs resistant to infarction from subsequent sustained ischemia and reperfusion [7]. This mechanism not only offers protection of the tissue subjected to brief ischemia, but also renders myocardium resistant to ischemia by exposure of a remote organ to an IPC stimulus [8,9]. This discovery has greatly facilitated the ability to translate this concept into a clinical applicability. Remote ischemic conditioning (RIC) by subjecting an arm to intermittent short periods of ischemia and reperfusion increases myocardial salvage in patients with evolving myocardial infarction [10], reduces release of troponin in patients undergoing heart surgery [11,12], and reduces cerebral damage in stroke patients [13].

One of the earliest responses to cellular stress is a rapid and global increase in the rate of O-GlcNAcylation, a dynamic posttranslational glycosylation of a variety of proteins [14]. This increase facilitates stress tolerance and cell survival, and has been shown to be protective [15]. An increase of intracellular O-GlcNAc levels protects against IR injury. Pharmacological and genetic augmentations of O-GlcNAc levels in isolated perfused hearts reduce infarct size when subjected to IR injury [16-19]. $\mathrm{O}-$ GlcNAc is also involved in protection against IR injury by ischemic conditioning. IPC has been shown to increase myocardial O-GlcNAc levels in rodents [20-22]. RIC has been shown to increase myocardial O-GlcNAc levels in human atrial trabeculae [23]. Blocking O-GlcNAcylation abrogated the cardioprotective effect of RIC in human atrial trabeculae [23].

The aim of the present review is to evaluate the impact of current research on the underlying mechanisms behind the interaction between O-GlcNAcylation and protection against IR injury. However, specific research on the effects of O-GlcNAcylation in IR injury is limited, so we critically evaluated whether the protective mechanisms associated with O-GlcNAcylation from studies conducted in other models may be extrapolated to the settings of IR injury.

\section{O-Linked $\beta$-N-Acetylglucosamine (O-GlcNAc)}

O-linked $\beta-\mathrm{N}$-acetylglucosamine (O-GlcNAc) is a dynamic posttranslational modification of nuclear, cytoplasmatic, and mitochondrial proteins through the hexosamine biosynthetic pathway (HBP) (Figure 1). 


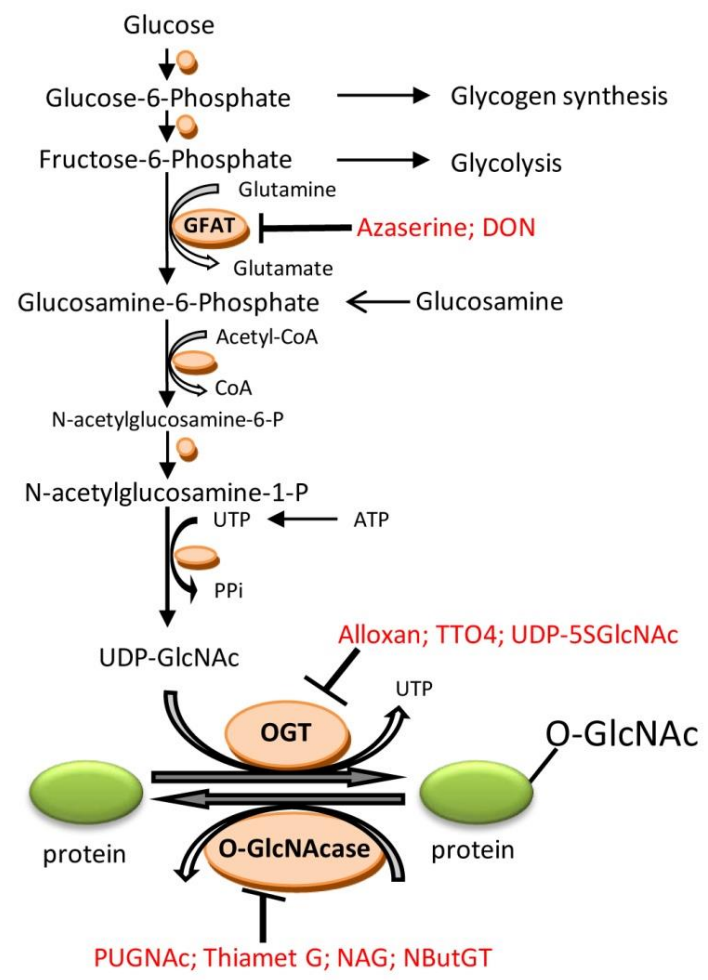

Figure 1. The hexosamine biosynthsis pathway (HBP) and protein O-GlcNAcylation. Enzymes are illustrated by orange circles. Blockers are written in red. Abbreviations: GFAT: L-glutamine-D-fructose 6-phosphate amidotransferase; UDP-GlcNAc: UDP-N-acetylglucosamine; OGT: uridine-diphospho-N-acetylglucosamine:polypeptide $\beta$-N-acetylglucosaminyltransferase; O-GlcNAcase: $\beta-N$-acetylglucosaminidase; DON: 6-diazo-5-oxo-norleucine; UDP-5SGlcNAc: uridine diphospho-5thio-N-acetylglucosamine; TTO4: 2[(4-chlorophenyl)imino]tetrahydro-4-oxo-3-[2-tricyclo(3.3.1.13.7)dec-1ylethel]; PUGNAc: O-(2-acetamido-2-deoxy-D-glucopyranosylidene)amino-N-phenylcarbamate; NAG: 1,2-Dideoxy-2'-methyl- $\alpha$-D-glucopyranoso-[2,1-d]- $\delta 2$ '-thiazoline; NButGT:1,2-dideoxy-2'-propyl- $\alpha$-dglucopyranoso-[2,1-d]- $\delta 2^{\prime}$-thiazoline. GFAT can be inhibited by glutamine analogue azaserine (O-diazoacetyl-L-serine) or DON. OGT can be inhibited by the uridine analogue alloxan, substrate analog of O-GlcNAc UDP-5SGlcNAc, or with TTO4, whereas O-GlcNAcylation of proteins can be rapidly increased by inhibiting O-GlcNAcase with PUGNAc, Thiamet G, NAG, or NButGT. Alloxan has also shown to have an inhibitory effect on O-GlcNAcase.

The initial step of the HBP transforms fructose-6-phosphate to glucosamine-6-phosphate by the enzyme L-glutamine-D-fructose-6-phosphate amidotransferase (GFAT). Through several enzymatic steps, glucosamine-6-phosphate is converted into uridine- diphosphate- $\mathrm{N}$-acetylglucosamine (UDP-GlcNAc), which acts as substrate for the enzyme that catalyzes the addition of $\mathrm{O}-\mathrm{GlcNAc}$ to serine and threonine residues, uridine-diphospho-N-acetylglucosamine:polypeptide$\mathrm{N}$-acetylglucosaminyltransferase (OGT). The removal of O-GlcNAc is catalyzed by $\beta$-hexoamininidase (O-GlcNAcase). In experimental settings, the formation of O-GlcNAc can be augmented pharmacologically by increasing flux through HBP using glucosamine $[24,25]$ or glutamine treatment [18], or pharmacologic inhibition of O-GlcNAcase with O-(2-acetamido-2-deoxy-Dglucopyranosylidene)amino-N-phenylcarbamate (PUGNAc) [24,26], Thiamet G [27], or 1,2-Dideoxy2'-methyl- $\alpha$-D-glucopyranoso[2,1-d]- $\delta 2$ '-thiazoline (NAG-thiazoline) [16], or 1,2-dideoxy-2'-propyl- $\alpha$ d-glucopyranoso-[2,1-d]- $\delta 2^{\prime}$-thiazoline (NButGT) [25], and through genetic inhibition of O-GlcNAcase by transfection with short interfering (si) RNA directed against O-GlcNAcase [26] or genetic increase in OGT expression [28,29], by adenoviral overexpression. O-GlcNAcylation can be blocked by pharmacologic GFAT inhibition with the glutamine analogue azaserine (o-diazoacetyl-L-serine) [18,23,24], or GFAT inhibitor 6-diazo-5-oxo-norleucine (DON) [30], or OGT 
inhibition with uridine analogue alloxan [24,31] or with 2[(4-chlorophenyl)imino]tetrahydro-4-oxo3-[2-tricyclo(3.3.1.13.7)dec-1-ylethel] (TTO4) [27], or substrate analog of O-GlcNAc uridine diphospho-5-thio-N-acetylglucosamine (UDP-5SGlcNAc) [32]. Unfortunately none of the enzyme blockers are entirely specific [22,33]. Alloxan has inhibitory effects on both OGT and O-GlcNAcase [33]. O-GlcNAcylation can also be blocked genetically by adenoviral overexpression of O-GlcNAcase [26], inhibition of OGT by transfection with short interfering (si) RNA directed against OGT [28], or genetic deletion of OGT using a cre-lox approach [28].

O-GlcNAc modification plays an important role in numerous biological processes, both in normal cell functions such as regulating cell cycle [34], protease activity [35], and transcription [36,37], and in the etiology of chronic disease. Transient elevation of O-GlcNAc in relation to stress is protective, as discussed below, while chronic elevation of O-GlcNAc plays a role in the pathophysiological processes of neurodegeneration in Alzheimer's [38] and Parkinson's disease[39]; cancer [40]; hypertension; cardiac hypertrophy and failure [41]; complications of diabetes mellitus, particularly insulin resistance [42]; increased atherosclerosis [43]; and cardiac dysfunction [44].

In mammalian cells multiple stress varieties, such as chemical, thermal, and biological stimuli, increase O-GlcNAcylation of nuclear and cytoplasmatic proteins. A reduction of O-GlcNAc levels, achieved by deletion of OGT, sensitizes cells to thermal stress, while augmentation of O-GlcNAc by genetic overexpression of OGT or pharmacologic inhibition of O-GlcNAcase with PUGNAc increases thermal tolerance and improves cell survival [14]. Accordingly, augmentation of intracellular O-GlcNAc levels is protective against IR injury in various experimental models. In neonatal rat ventricular myocytes, an increase of protein O-GlcNAcylation by inhibition of O-GlcNAcase pharmacologically with PUGNAc [24,26] or NAG-thiazoline derivative [25], or genetically by RNA interference of O-GlcNAcase [26], improves survival following IR injury. Moreover, an increase of O-GlcNAc levels by glucosamine treatment or genetic augmentation of OGT expression by adenovirus transfection attenuates cardiac myocyte death following hypoxia-reoxygenation $[25,28]$. Reduction in O-GlcNAc levels by pharmacologic (alloxan or TT04) [24,28] or genetic OGT inhibition [28], or genetic overexpression of O-GlcNAcase [26], exacerbated myocyte death.

In isolated perfused hearts, increasing cardiac O-GlcNAc levels by perfusion with glucosamine or glutamine $[17,18]$, subjection to O-GlcNAcase inhibitor PUGNAc [19], or NAG-thiazoline derivatives [16] reduced myocardial damage when subjected to IR injury. Additional support for the cardioprotective effect of O-GlcNAc was given in studies demonstrating that the increase in myocardial O-GlcNAc levels and the protective effect of glucosamine was blocked by inhibition of OGT with alloxan or inhibition of GFAT with azaserine [17,18].

An increase in cerebral O-GlcNAc levels by glucosamine treatment has been shown to be neuroprotective against IR injury. In a rat middle cerebral artery occlusion model, intraperitoneal glucosamine administration reduced cerebral infarct size and afforded reduction in motor impairment and neurological deficits [45].

In 2008, Jones et al. used a mouse model to demonstrate that IPC increased cardiac O-GlcNAc levels and reduced infarct size after $30 \mathrm{~min}$ of left coronary artery ligation and $24 \mathrm{~h}$ of reperfusion [20]. In an isolated perfused rat heart model, we confirmed in two studies that IPC reduces infarct size and increases cardiac O-GlcNAc levels [21,22]. In the first study, the increase in O-GlcNAc was induced by enhanced OGT expression and activity [22]. In the second study, we demonstrated that cardioprotection by IPC was associated with increased myocardial glucose uptake, which may also contribute to the mechanism by which IPC increases O-GlcNAc levels [21]. To test the influence of O-GlcNAc in protection by the more clinically relevant RIC, we demonstrated that dialysate from healthy volunteers exposed to RIC improved post-ischemic recovery and increased myocardial O-GlcNAc levels in human isolated atrial trabeculae subjected to IR injury (Figure 2) [23]. The cardioprotective effect and the increase in O-GlcNAc were abolished by the GFAT inhibitor azaserine. In human non-diabetic trabeculae, the increase in O-GlcNAc afforded by dialysate from healthy volunteers subjected to RIC was associated with increased OGT activity and decreased O-GlcNAcase activity [23]. 
In conclusion, an increase of cardiac O-GlcNAc levels is protective against IR injury. The protection has been demonstrated in many different models, including cells, isolated heart models, and in vivo. Protection against IR injury following IPC and RIC is associated with increase in O-GlcNAc levels, predominately through increased OGT activity and increased glucose uptake.

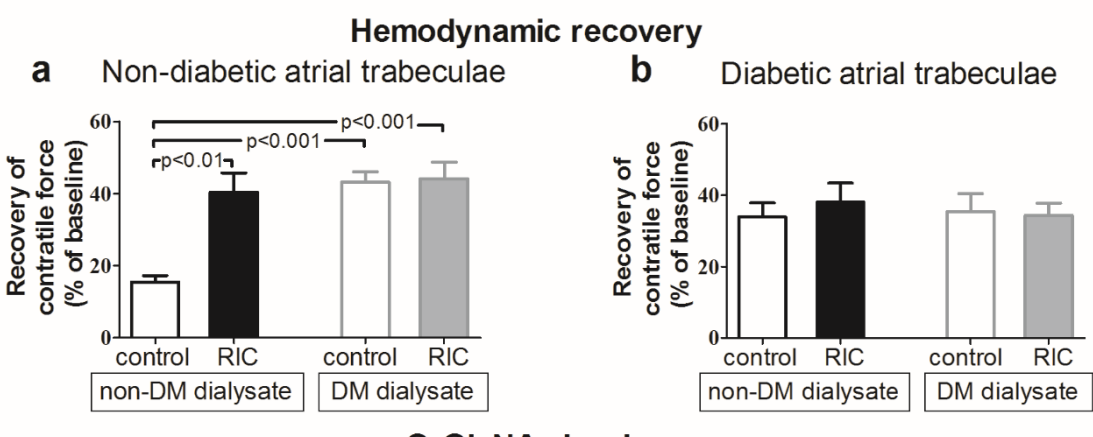

O-GIcNAc levels

C Non-diabetic atrial trabeculae

d Diabetic atrial trabeculae
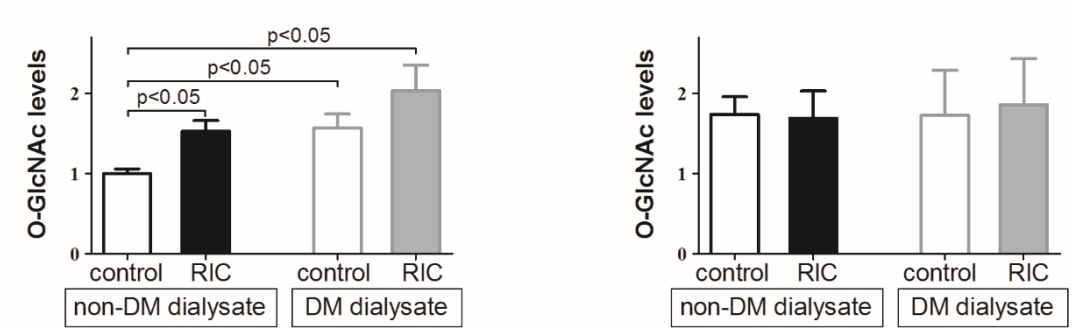

OGT activity

e Non-diabetic atrial trabeculae

f Diabetic atrial trabeculae
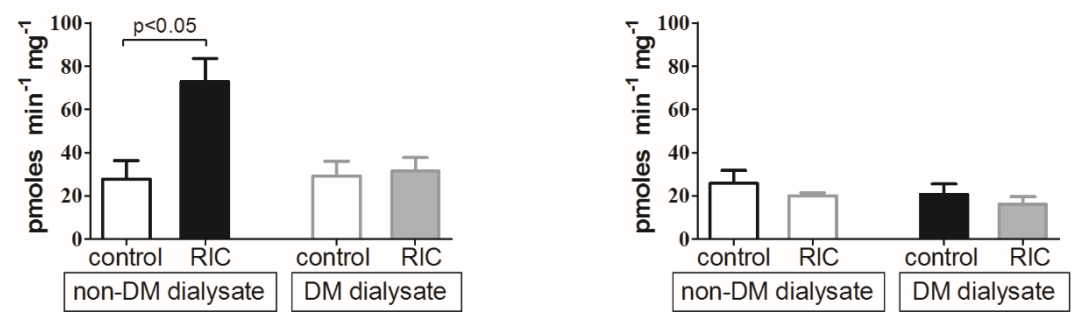

O-GIcNAcase activity

g Non-diabetic atrial trabeculae

h Diabetic atrial trabeculae
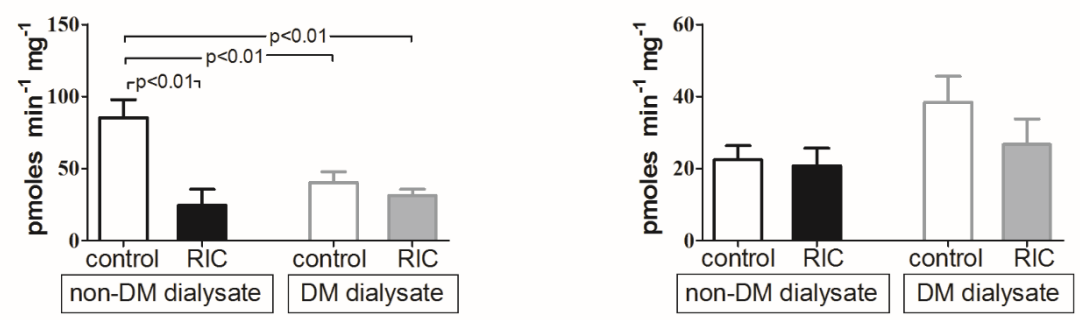

Figure 2. $(\mathbf{a}, \mathbf{b})$ Recovery of contractile force in atrial trabeculae from non-diabetic (a) and diabetic (b) patients, perfused with control and RIC dialysate from non-diabetic and diabetic patients; $(\mathbf{c}, \mathbf{d})$ O-GlcNAc levels in atrial trabeculae from non-diabetic (c) and diabetic (d) patients, perfused with control and RIC dialysate from non-diabetic and diabetic patients; (e,f) OGT activity in atrial trabeculae from non-diabetic (e) and diabetic (f) patients, perfused with control and RIC dialysate from non-diabetic and diabetic patients; $(\mathbf{g}, \mathbf{h}) \mathrm{O}-\mathrm{GlcNAcase}$ activity in atrial trabeculae from non-diabetic (g) and diabetic (h) patients, perfused with control and RIC dialysate from non-diabetic and diabetic patients. Data are mean \pm SEM. Originally published Cardiovasc Res. 2013 Feb 1; 97(2): 369-378 [23]. Reproduced with permission. 


\section{Mechanisms by Which O-GlcNAc Confers Protection}

\subsection{Calcium Overload}

Calcium overload contributes to the detrimental cascade of IR injury. Similar to the effect of IPC [46,47], increasing O-GlcNAc levels by glucosamine treatment protected against injury resulting from calcium paradox [17]. The calcium paradox was established in isolated perfused rat hearts, where calcium-free perfusion followed by perfusion with buffer containing physiological calcium concentration led to cardiomyocyte injury [48,49]. Glucosamine treatment also blocked ANG-II-induced calcium overload in neonatal rat ventricular myocytes [31]. The beneficial effects were dependent on OGT [31]. More importantly, O-GlcNAc also attenuates calcium overload in IR injury. In neonatal rat ventricular myocytes, glucosamine treatment and OGT overexpression increased O-GlcNAc levels and attenuated hypoxia-induced calcium overload during reoxygenation, when assessed by time-lapse fluorescence microscopy [24,50]. O-GlcNAcylation is known to be one of the regulators of the inositol 1,4,5-trisphosphate (InsP3) receptor type I, a channel for intracellular calcium release in many cell types [51].

In conclusion, O-GlcNAc may be involved in protection against IR injury through attenuation of calcium overload (Figure 3). The mechanisms by which O-GlcNAc attenuates calcium overload are not known. O-GlcNAc may regulate other calcium channels in the endoplasmic reticulum $[51,52]$ or mitochondria, but currently no evidence documents this speculation.

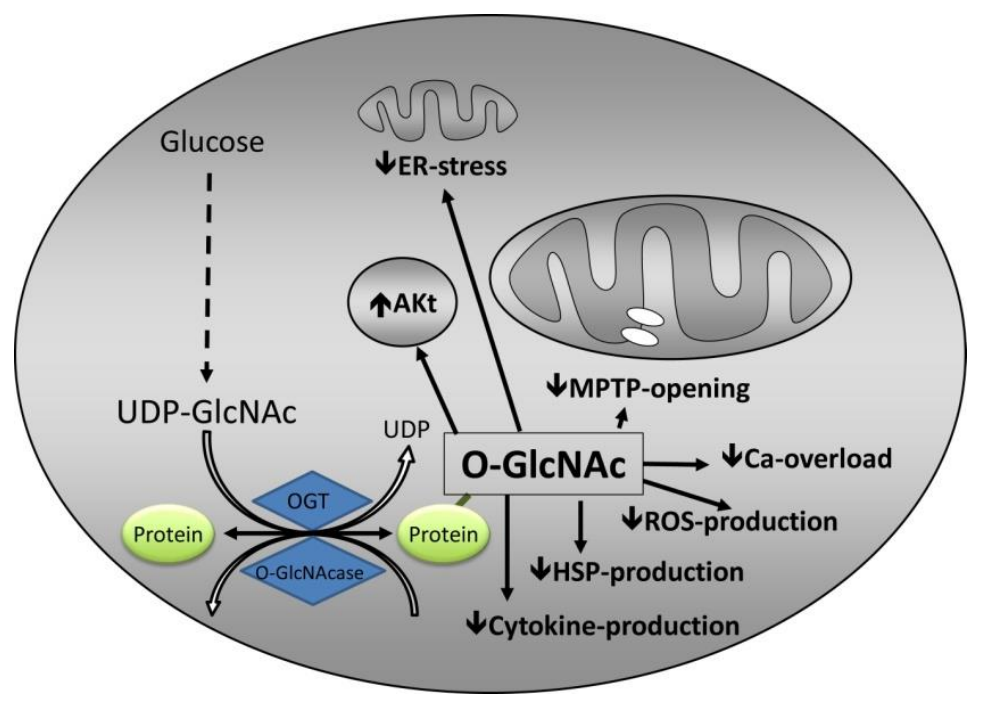

Figure 3. Summary of potential mechanisms by which O-GlcNAc confers protection. The mechanisms involve attenuation of endoplasmic reticulum (ER) stress, interaction with established cardioprotective pathways, predominantly Akt, inhibition of mitochondrial permeability transition pore (MPTP), attenuation of calcium overload, reactive oxygen species (ROS), heat shock protein (HSP), and cytokine production that reduce systemic inflammatory response. Other abbreviations as in Figure 1.

\section{2. mPTP Opening}

Opening of the mitochondrial permeability transition pore (mPTP) is considered to be a critical step in cellular death from IR injury. Opening of the MPTP causes depolarization of the mitochondria, influx of solutes and water, mitochondrial swelling, rupture, and release of pro-apoptotic factors as cytochome C [53-55].

The effect of O-GlcNAcylation on ROS generation in the setting of IR injury has been sparsely evaluated. It has been demonstrated that augmenting O-GlcNAc levels by adenoviral OGT overexpression or PUGNAc treatment attenuated hypoxia and oxidative stress-induced ROS generation [50]. Notably, in contrast to this study, O-GlcNAcylation is thought to promote ROS 
generation in models of hyperglycemia and glucose toxicity [56]. The interplay between O-GlcNAc and ROS is complex and not fully understood $[57,58]$. In the setting of chronic elevation of O-GlcNAc by hyperglycemia or glucosamine treatment, ROS generation was elevated and cell death induced [59], while more acute increase in O-GlcNAcylation attenuated ROS generation [50].

Increased intracellular O-GlcNAc levels attenuate the loss of mitochondrial membrane potential. In neonatal rat cardiac myocytes, augmentation of O-GlcNAc levels by treatment with PUGNAc, glucosamine, OGT overexpression, or O-GlcNAcase inhibition with a NAG-thiazoline derivative significantly attenuated loss of mitochondrial membrane potential in a dose-dependent manner after exposure to $\mathrm{H}_{2} \mathrm{O}_{2}$, as assessed by fluorescent cationic dye, JC-1, or TMRE fluorescence [20,25]. Increased O-GlcNAc levels also attenuated IR-induced loss of mitochondrial membrane potential. Genetic overexpression of OGT, or inhibition of O-GlcNAcase, increased O-GlcNAc and protected neonatal rat cardiac myocytes from cell death following hypoxia-reoxygenation, and aggravated the loss of mitochondrial membrane potential assessed by changes in TMRE fluorescence. Pharmacologic inhibition of OGT with TT04 exacerbated the loss of mitochondrial membrane potential and cell death $[26,28]$.

Substantial evidence documents that increased cardiac O-GlcNAc levels attenuate mPTP opening $[20,25,28,50,60]$. Ngoh et al. demonstrated that in neonatal rat ventricular myocytes, increased cardiac O-GlcNAc levels by OGT overexpression significantly delayed $\mathrm{H}_{2} \mathrm{O}_{2}$ mediated mPTP opening, as assessed by changes in calcein fluorescence using time-lapse fluorescence microscopy, while O-GlcNAcase overexpression accelerated $\mathrm{H}_{2} \mathrm{O}_{2}$ mediated mPTP formation [50]. O-GlcNAcase inhibition with PUGNAc significantly mitigated mPTP formation [50]. Hirose et al. showed that isoflurane treatment was cardioprotective in mice and in cardiomyocytes, and was associated with elevation in O-GlcNAc levels [60]. The cardioprotective effect and increase in O-GlcNAc levels were eliminated by the OGT inhibitor alloxan. Similar to Ngoh's findings, Hirose showed that the cardioprotective effect was associated with a delay of $\mathrm{H}_{2} \mathrm{O}_{2}$ mediated mPTP opening in isolated adult cardiomyocytes, and the effect was abrogated by OGT inhibition [60]. Following IR of isolated neonatal rat ventricular myocytes, increasing O-GlcNAc levels by glucosamine treatment, OGT overexpression, and O-GlcNAcase inhibition using a NAG-thiazoline derivative decreased cytochrome $\mathrm{C}$ release, reflecting attenuated mPTP opening [25]. Increasing cardiac O-GlcNAc levels enhanced the resistance of isolated mitochondria cardiomyocytes towards calcium-induced mitochondrial swelling [20], also reflecting attenuated mPTP opening. Accordingly, reduction in cardiac O-GlcNAc levels sensitized isolated mitochondria to calcium-induced mitochondrial swelling [28].

The mechanism by which O-GlcNAc inhibits mPTP opening is not known, mainly because the exact structure of the MPTP is not established and the identity and function of a variety of subunits are not clear. The MPTP is thought to consist of several subunits that include several factors modifying the transporter function. It is widely accepted that the pore consists of the voltage-dependent anion channel (VDAC) in the mitochondrial outer membrane, the adenine nucleotide translocase (ANT) in the mitochondrial inner membrane, the matrix protein cyclophilin D, and complex V ATP synthase. Interaction between these subunits increases the sensitivity of the mPTP to calcium. The interaction can be prevented in several ways [61]. Cyclosporine A inhibits MPTP opening through cyclophilin D inhibition [62], while anti-apoptotic factors such as Bcl-2 interact with ANT to hinder opening of the mPTP [61].

Mitochondrial subunit VDAC is subject to O-GlcNAc modification. In isolated cardiomyocytes, PUGNAc elevated global O-GlcNAc levels and increased O-GlcNAcylation of the VDAC subunit, while the cardiomyocytes simultaneously became more resistant to calcium-induced swelling compared with those treated with vehicle $[20,28,60]$. O-GlcNAc also influences Bcl-2 levels. In neonatal rat ventricular myocytes, glucosamine and OGT transfection increased O-GlcNAc levels, attenuated cell injury following IR injury, increased mitochondrial Bcl-2 levels, and attenuated mitochondrial-mediated apoptosis evaluated by assessment of cytochrome $\mathrm{C}$ loss [25]. Whether O-GlcNAcylation of VDAC or 
the $\mathrm{O}-\mathrm{GlcNAc}$ induced increase in $\mathrm{Bcl}-2$ prevents a direct interaction between the subunits and the mPTP opening is not known.

Taken together, available data indicate that increased O-GlcNAc protects against IR injury by attenuation of mPTP opening (Figure 3). The mechanisms are not fully understood, and it is not known whether a direct effect of increased intracellular O-GlcNAc content and O-GlcNAcylation of mPTP subunits, or an indirect effect through attenuation of calcium overload and ROS production prevails.

\subsection{Endoplasmic Reticulum Stress}

The endoplasmic reticulum (ER) maintains synthesis, folding, and transport of proteins. Exposure to stress, such as IR, provokes ER stress, potentially leading to increases in unfolded proteins and subsequent apoptosis [63,64]. Activation of the unfolded protein response (UPR) promotes re-establishment of normal ER function, but prolonged ER stress activates a maladaptive response of UPR ultimately leading to apoptosis. The transcription factor CCAAT-enhancer-binding protein homologous protein (CHOP) is also involved in ER stress-induced apoptosis $[65,66]$, and PERK-mediated phosphorylation of eIF $2 \alpha$ is thought to play a dominant role in the induction of CHOP in response to ER stress $[67,68]$.

O-GlcNAc mediated protection against IR injury may partially be mediated by modulation of ER stress. In neonatal rat ventricular myocytes, pharmacological O-GlcNAcase inhibition using PUGNAc augmented O-GlcNAc levels and reduced brefeldin A-induced ER stress, according to UPR-inducible proteins Grp94, Grp78, and calreticulin levels. Increased O-GlcNAc levels blocked the activation of maladaptive ER stress response as reflected by diminished CHOP activation, and mitigated ER stress-induced cell death but not apoptosis, according to caspase-3/7 activity [29]. In a rabbit model of renal ischemia, glucosamine treatment increased O-GlcNAc levels and protected against renal damage. Glucosamine attenuated increase in CHOP and GRP78 expression during hypoxia, and decreased the proportion of apoptotic cells [69].

O-GlcNAc may protect cells against ER stress-induced apoptosis through regulation of eIF2 $\alpha$ phosphorylation. In HepG2 cells, augmentation of O-GlcNAc levels by Thiamet G treatment or OGT overexpression showed that eIF2 $\alpha$ was O-GlcNAcylated at Ser 219, Thr 239, and Thr 241, hindering phosphorylation of eIF2 $\alpha$ and reducing CHOP activation [70]. Point mutation of the O-GlcNAcylation sites of eIF $2 \alpha$ increased eIF $2 \alpha$ phosphorylation and CHOP activation, and was associated with increased apoptosis upon ER stress [70].

Overall, O-GlcNAc mediated protection against IR injury seems to involve a reduction of ER stress (Figure 3) through attenuated induction of CHOP, presumably by inhibition of eIF $2 \alpha$ phosphorylation.

\subsection{Inflammation}

IR injury induces an inflammatory response with release of cytokines, activation of the complement system, and activation of neutrophils [71]. IR also activates Nuclear Factor kappa-B (NF- $\mathrm{KB}$ ) during reperfusion, which may have a detrimental effect, as inhibition of NF- $\mathrm{kB}$ improves outcome after IR injury [72,73]. In contrast, NF- $\mathrm{kB}$ activation may have a beneficial role in IPC. A preconditioning stimulus seems to activate NF- $\mathrm{KB}$, and pharmacological inhibition of NF- $\mathrm{KB}$ abolishes the cardioprotective effect of preconditioning [74,75]. The finding is ambiguous because protection in some models, including models of non-cardiac IPC, is associated with depression of NF-кB [76-78].

O-GlcNAc has anti-inflammatory effects in a variety of cell types and models [79-82].

In a model of endoluminal arterial injury, the increase of proinflammatory mediator expression (chemokines and adhesion molecules) was attenuated, and glucosamine or PUGNAc reduced infiltration of leukocytes after balloon injury of the carotid artery [83].

Increased O-GlcNAcylation by glucosamine or Thiamet $\mathrm{G}$ administration has a neuroprotective effect against IR injury through suppression of inflammation. Glucosamine and Thiamet $G$ treatment suppress induction of proinflammatory markers, IL1b, IL6, TNF- $\alpha$, iNOS, and COX-2 [45,84]. Studies 
investigating the protection by O-GlcNAc through anti-inflammatory effects in classic IR injury models beyond neuroprotection are scarce.

In a trauma-hemorrhagic shock model, PUGNAc administration increased O-GlcNAc levels, improved cardiac function after resuscitation, and reduced plasma tumor necrosis factor- $\alpha$ (TNF- $\alpha$ ) and interleukin-6 (IL-6) levels $2 \mathrm{~h}$ after resuscitation [85,86], while inflammatory cytokines did not differ $24 \mathrm{~h}$ after resuscitation [87]. In a similar model using not-resuscitated animals, glucosamine treatment had no effect on TNF- $\alpha$ and IL-10 release [88], suggesting that reperfusion is necessary for this protection mechanism to be involved. In a model of trauma-hemorrhagic shock and resuscitation, an increase of cardiac O-GlcNAc levels by glucosamine treatment was associated with attenuation of NF- $\mathrm{KB}$ activation. The nuclear translocation of NF- $\mathrm{KB}$ that leads to an inflammatory and immune response is dependent on the phosphorylation of IкB- $\alpha$, which leads to degradation by the proteasome. Glucosamine attenuated the increase of IкB- $\alpha$ phosphorylation and the subsequent NF-KB nuclear translocation, as well as the attenuation of the increase of mRNA of TNF- $\alpha$, IL-6, and ICAM-1 expression. Neutrophil infiltration was reduced, as evaluated by reduced MPO activity [89]. Similarly, in cultured cardiomyocytes, OGT overexpression attenuated LPS-induced increase in IкB- $\alpha$ phosphorylation, ICAM-1, TNF- $\alpha$ levels, and NF- $\mathrm{kB}$ activation, while increased O-GlcNAc levels by glucosamine treatment of mouse macrophage cells attenuated LPS-induced IкB- $\alpha$ phosphorylation and iNOS expression [89]. Potential mechanisms by which O-GlcNAc attenuates NF-kB activation are not clear, but may be by decreased I $\kappa \mathrm{B}-\alpha$ by inhibition of proteasome activity [90].

In vascular smooth muscle cells and human umbilical vein endothelial cells, increased O-GlcNAc levels by PUGNAc or glucosamine treatment attenuated the TNF- $\alpha$ induced activation of NF- $\mathrm{kB}[91,92]$. Phosphorylation of the p65 subunit of NF- $\mathrm{KB}$ is required for the transcriptional activation of NF-kB. Glucosamine or PUGNAc treatment increased O-GlcNAcylation of p65 subunit of NF- $\mathrm{B}$, which attenuated the TNF- $\alpha$-induced phosphorylation of p65 subunit of NF- $k B$, subsequently inhibiting activation of NF- $\mathrm{KB}$ and NF- $\mathrm{KB}$ mediated inflammatory response [91,92]. In a similar model, augmentation of O-GlcNAc protected against TNF- $\alpha$ induced oxidative stress and vascular dysfunction, while associated with inhibiting iNOS expression and suppressing the nitrotyros(yl)ation of proteins [93]. Additionally in neuroprotection, a potential mechanism by which O-GlcNAc protects against IR injury and O-GlcNAc regulates NF- $\mathrm{kB}$ activation could be by inhibiting translocation of p65 [84].

Thus, available data suggest that O-GlcNAc mediated protection against IR injury involves suppression of the inflammatory response through reduced induction of proinflammatory markers (Figure 3), and attenuated NF- $\mathrm{kB}$ activation by hindering IкB- $\alpha$ phosphorylation and translocation of 655 .

\subsection{Heat Shock Proteins}

Heat shock proteins (HSP) are a group of proteins produced by the cell in response to stress stimuli. They play a crucial role as chaperones in cell-cycle control, stabilizing, repair, folding, and unfolding of proteins $[84,94]$. O-GlcNAc is involved in regulating the expression of numerous HSPs. Elevating O-GlcNAc levels augments expression of HSPs by heat stress [14,95], while decreasing O-GlcNAc suppresses expression of HSPs [96]. Expression of HSP70 and HSP72 may be protective against IR injury through repression of apoptosis [97-99], because they are upregulated by a RIC stimulus [100]. Jones et al. showed that HSP70 levels were increased in cardiomyocytes that were protected by PUGNAc against $\mathrm{H}_{2} \mathrm{O}_{2}$ injury [20]. Whether the augmentation of $\mathrm{HSP70}$ was required for conferring protection was not determined. In a study by Wischmeyer et al., administration of glucosamine reduced infarct size after IR injury, but the authors found no change in HSP72 or HSP73 during the course of the experiment [101]. HSP70 physically interacts with O-GlcNAc proteins through a lectinic activity [102], such that O-GlcNAc seems to modify protein stability through specific interaction with 70-kDa-HSP members. 
O-GlcNAc may induce cardioprotection by stabilizing protein structure. However, further studies are needed to determine the interaction between O-GlcNAc, HSP and protection against IR injury.

\subsection{Interaction with Established Cardioprotective Pathways}

The reperfusion injury salvage kinase pathway (RISK) conveys the cardioprotective stimulus by IPC from the cell surface to the mitochondria through activation of survival kinases and cytokines in the beginning of reperfusion. IPC activates PI3K, Akt, and downstream kinases such as GSK $\beta$ by phosphorylation in a biphasic manner after the IPC stimulus, and in the beginning of reperfusion [103,104]. Knowledge about the interaction between O-GlcNAc and PI3K/Akt signaling in relation to protection against IR injury is scarce. An interplay between O-GlcNAc and Akt phosphorylation has been acknowledged, but the biological significance has not been fully characterized and understood [105]. While O-GlcNAcylation has been reported in some studies to impair the Akt phosphorylation, resulting in insulin resistance [106] and induction of apoptosis $[107,108]$, studies in other settings report that the interplay between O-GlcNAc and Akt inhibits apoptosis and provide cytoprotection in the kidney [109] and the liver [110].

$\mathrm{Hu}$ et al. suggested that acute augmentation of O-GlcNAc confers renal protection through activation of PI3K/Akt. In this study, administration of glucosamine increased O-GlcNAc levels and conferred renal protection against contrast-induced acute kidney injury. Augmented O-GlcNAc signaling increased phosphorylation of Akt in Ser473, but not in Thr 308 and Thr450, and GSK-3 $\beta$ in Ser9. The OGT inhibitor alloxan and the PI3K inhibitors Wortmannin and LY294002 blocked the renoprotective effect. Immunoprecipitation demonstrated that O-GlcNAc modified Akt activity in renal tissue [109]. In isolated cardiomyocytes subjected to hypoxia/reoxygenation stimulus, Akt phosphorylation was increased during the first $30 \mathrm{~min}$ of reoxygenation. Pretreatment with Thiamet $\mathrm{G}$ increased cell survival with no change in activation of Akt. Akt phosphorylation during reoxygenation was enhanced by O-GlcNAcase inhibition with TT04, while cell survival decreased it [27]. Hence, activation of Akt does not appear to be a mechanism of Thiamet G-mediated cytoprotection. However, Akt phosphorylation may not have been measured in a timely way during reoxygenation, compared to the changes in Akt described in the RISK pathway [101,103].

Other established pathways in protection against IR injury by IPC are the survivor activating factor enhancement (SAFE) pathway [111] and nitric oxide (NO) pathway. O-GlcNAcylation generally suppresses induction of TNF- $\alpha$, which is activated in IPC [112]. The interplay between O-GlcNAc and signal transducer and activator of transcription or NO-pathways has not to our knowledge been investigated in the IR injury.

Thus, cardioprotection involves an interaction between O-GlcNAc and Akt (Figure 3), but it is not clear whether O-GlcNAc mediated protection involves the RISK pathway.

\subsection{Impact of O-GlcNAcylation on Cardiac Function}

As in skeletal muscle (for recent review see [113]), several contractile and regulatory proteins of cardiac muscle have been identified as being O-GlcNAcylated [114]. These observations strongly support the idea that O-GlcNAcylation is involved in the regulation of contraction, or in its dysfunction. $\mathrm{O}-$-GlcNAc is essential for cell viability. While acute activation of pathways that increase O-GlcNAc levels improves tolerance of cells to a wide range of stress stimuli, sustained increase in O-GlcNAc levels has been implicated in chronic disease states, in particular as a pathogenic contributor to insulin resistance [42] and diabetic complications [115]. The consequences of chronically elevated O-GlcNAc linked to metabolic disease may compromise cardiomyocyte [44] as well as vascular function [116]. The contrasting beneficial effect of acute elevation of O-GlcNAc levels demonstrate that this posttranslational modification system is extremely dynamic. However, the fundamental mechanisms involved in regulating O-GlcNAc turnover and the precise regulation of its functional consequences still remain limited. 


\subsection{Impact of Diabetes Mellitus on O-GlcNAcylation and Cardioprotective Efficacy}

Diabetes mellitus is associated with increased O-GlcNAcylation of intracellular proteins in several cells and tissues, including cardiomyocytes [23], renal cells [117], pancreatic cells [118], erythrocytes [119], and cornea [120]. Chronically increased O-GlcNAcylation contributes to complications of diabetes mellitus, particularly insulin resistance [42], increased atherosclerosis [43], and cardiac dysfunction [44].

Studies in animal models have demonstrated that diabetic animals have reduced susceptibility to IR injury [121-126]. The tolerance is dependent on diabetes duration and the severity of diabetes [122,126]. We documented that O-GlcNAc levels were elevated in atrial trabeculae from diabetic patients, which was associated with improved hemodynamic function of the trabeculae. Perfusion of atrial trabeculae from non-diabetic patients with dialysate from diabetic volunteers increased O-GlcNAc levels, also conferring protection against IR injury (Figure 2) [23]. No further increase in O-GlcNAc levels and no additional protection were achieved by RIC in trabeculae perfused with dialysate from diabetic patients, or in trabeculae from diabetic patients, suggesting that type 2 diabetes per se activates, through augmentation of O-GlcNAc levels, an inherent cardioprotective mechanism that may restrict further cardioprotection by RIC [23]. In a study of isolated hearts from young Zucker diabetic fatty rats, we found a upwards tendency, although not a statistically significant increase, in O-GlcNAc levels compared with non-diabetic rats. Diabetic rats were endogenously protected with significant reduced infarct size after IR injury during normoglycemic conditions, but not during hypoglycemia [21]. The association between IPC, infarct size reduction, and increase of O-GlcNAc levels was found in both diabetic and non-diabetic animals [21]. In streptozocin-induced diabetic isolated perfused hearts, diabetes improved recovery after exposure to the calcium paradox. The improvement was associated with an increase in cardiac O-GlcNAc levels [17].

Altogether, the chronic elevation of O-GlcNAcylation in diabetes mellitus is associated with complications of diabetes, but also seems to be involved in endogenous protection against IR injury.

\subsection{Pharmacological Modulation of O-GlcNAcylation and Role for Cardioprotection}

The most clinically applicably pharmacological modulation of O-GlcNAc levels can be achieved by glutamine or glucosamine treatment, because both compounds increase O-GlcNAcylation and induce cardioprotection against IR injury in rodents in vivo and in isolated heart models $[18,19,24,25,101]$, and rodents exposed to trauma hemorrhage [85,87-89]. In contrast, glutamine failed to provide any protective effect in pigs [127]. Cardiac O-GlcNAc levels were not measured in this study, so it cannot be ruled out that the lack of protection was due to an insufficient dose. The effect of oral glucosamine treatment remains controversial [128], which may be due to insufficient intestinal absorption to secure the needed increase in cardiac O-GlcNAc levels to induce cytoprotection.

Metformin induces cardioprotection against IR injury in the rat heart $24 \mathrm{~h}$ after administration [129]. The cardioprotective effect was associated with an increased AMPK activity, which is thought to be an important signal mediator of the cardioprotective effects by metformin. Although speculations about modification of O-GlcNAcylation may be attractive because metformin increases cellular glucose uptake, no available data support this assumption. In a streptozotocin-induced diabetic mouse model, eight days of metformin administration protected against retinal cell death by OGT inhibition and the interaction between OGT and NF- $\mathrm{KB}$ [130]. While NF- $\mathrm{KB}$ is an important regulator of programmed cell death, and elevated O-GlcNAc levels enhance NF- $\mathrm{KB}$ signaling, the findings may have implications for chronic glucotoxicity, but they can hardly be extrapolated to acute IR injury. While studies of glucose-insulin-potassium (GIK) infusion to patients undergoing cardiac surgery have shown a cardioprotective effect [131,132], GIK infusion to patients with ST-elevation myocardial infarction (STEMI) has yielded conflicting results about cardioprotective efficacy [133-135]. High dose GIK therapy offers no clinical benefit at 1 year in patients with STEMI without signs of heart failure treated with reperfusion therapy [136]. GIK treatment was associated with a significant increase in O-GlcNAcylation of selected protein bands in the Hypertrophy, Insulin, Glucose and Electrolytes 
(HINGE) trial [137]. While the underlying mechanisms may be several, including improved myocardial energy production efficiency during acute ischemia by high-dose glucose substituting depleted myocardial potassium levels during ischemia and suppression of circulating levels and myocardial uptake of free fatty acids, which are toxic to ischemic myocardium by insulin, the increased O-GlcNAcylation may be an additional mechanism that may explain the beneficial effects of GIK solution. Indeed, a recent experimental study demonstrated that glucose and insulin synergistically reduced ROS production, protected neonatal rat ventricular myocytes dose-dependently from apoptosis, and altered O-GlcNAc and OGT expression [138]. Efficacy seems to be dependent on early administration before reperfusion, and seems to be associated with activation of cardioprotective pathways rather than modulation of metabolism $[139,140]$.

Volatile anesthetics have protective effects against IR injury [141-143]. The cardioprotective effect of isoflurane is associated with increase in cardiac O-GlcNAc levels and abrogated by OGT inhibitor alloxan [60]. Isoflurane induces O-GlcNAc modification of mitochondrial voltage-dependent anion channel. This modification inhibits the opening of the MPTP, and confers resistance to ischemia-reperfusion stress.

In conclusion, available data do not identify specific pharmacological compounds that convincingly establish them as cardioprotective drugs by modulation of the HBP activity at present. Increase of cardiac O-GlcNAc may be involved in the mechanism underlying cardioprotection by volatile anesthetics, and supports the idea that pharmacologic modulation of O-GlcNAcylation may be a potential target for future pharmacologic treatment.

\section{Conclusions}

Increased intracellular O-GlcNAc content is cytoprotective against a variety of stress stimuli, including protection against IR injury. Studies on the involvement of O-GlcNAc in IPC are limited, but cardioprotection against IR injury by IPC seems to be associated with increased O-GlcNAc levels. Several of the mechanisms through which O-GlcNAc affords protection correlate with mechanisms underlying IPC, including attenuation of calcium overload, inhibition of mPTP opening, reduction of ER stress and apoptosis, suppression of the inflammatory response, and HSP expression. Thus, O-GlcNAcylation seems to be an inherent adaptive cytoprotective response to IR injury that may be activated by mechanical conditioning strategies.

Author Contributions: R.V.J. and H.E.B. wrote the manuscript. I.A., D.J.H. edited the manuscript.

Funding: This research was funded by Fondation Leducq (CVD06), The Danish Council for Strategic Research (11-108354), Novo Nordisk Foundation (Conditioning Based Intervention Strategies-ConBis) (NNF15OC0016674) and Trygfonden (109624). DJH was supported by the British Heart Foundation (CS/14/3/31002), the National Institute for Health Research, University College London Hospitals Biomedical Research Centre, Duke-National University Singapore Medical School, Singapore Ministry of Health's National Medical Research Council under its Clinician Scientist-Senior Investigator scheme (NMRC/CSA-SI/0011/2017) and Collaborative Centre Grant scheme (NMRC/CGAug16C006), and the Singapore Ministry of Education Academic Research Fund Tier 2 (MOE2016-T2-2-021). This article is based upon work from COST Action EU-CARDIOPROTECTION CA16225 supported by COST (European Cooperation in Science and Technology).

Conflicts of Interest: The authors declare no conflict of interest.

\section{Abbreviations}

$\begin{array}{ll}\text { ANT } & \text { Adenine nucleotide translocase } \\ \text { CHD } & \text { Coronary heart disease } \\ \text { CHOP } & \text { CCAAT-enhancer-binding protein homologous protein } \\ \text { DON } & \text { 6-diazo-5-oxo-norleucine } \\ \text { ER } & \text { Endoplasmic reticulum } \\ \text { GFAT } & \text { L-glutamine-D-fructose-6-phosphate amidotransferase } \\ \text { GIK } & \text { Glucose-insulin-potassium }\end{array}$




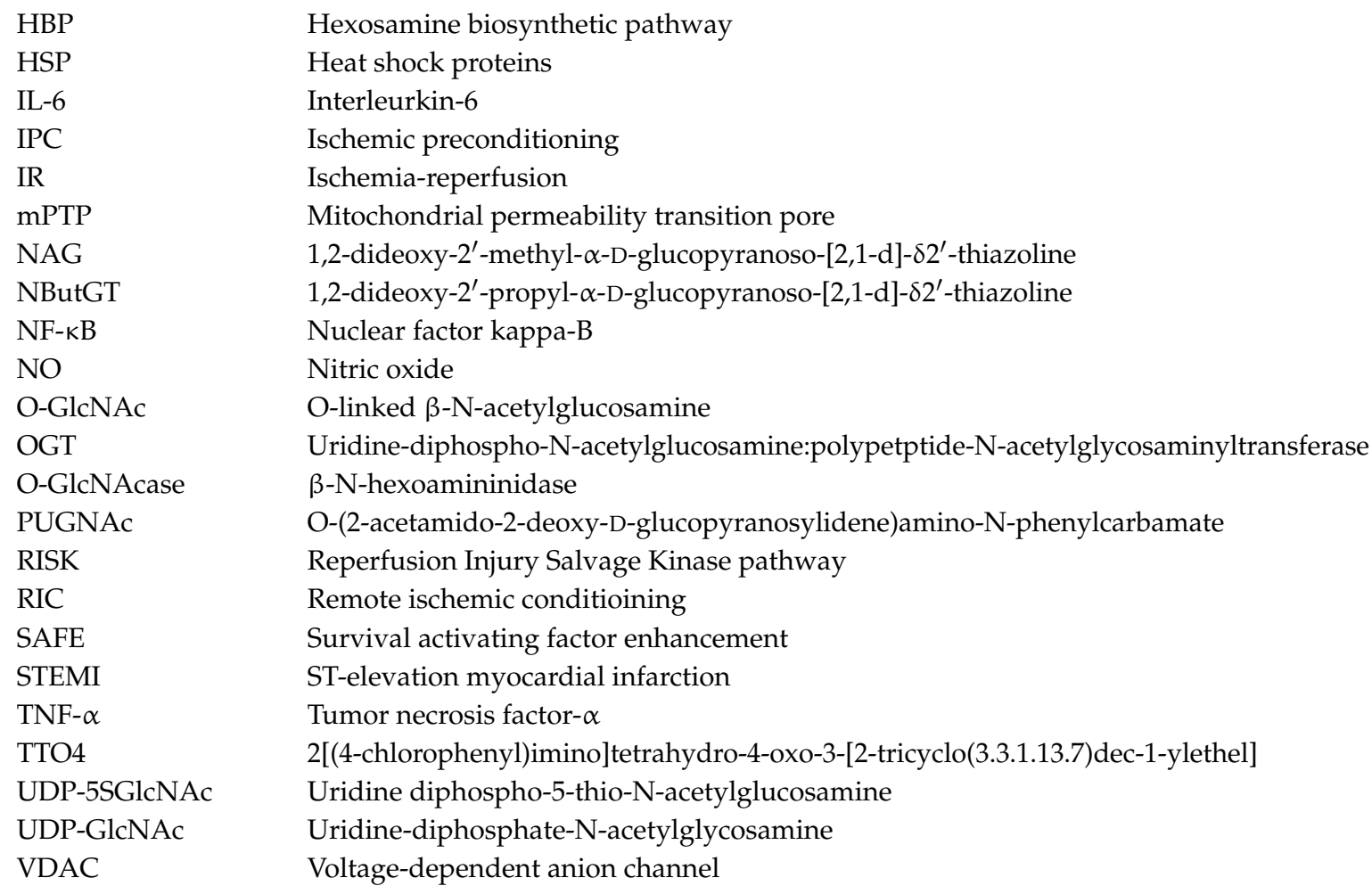

\section{References}

1. Burns, R.J.; Gibbons, R.J.; Yi, Q.; Roberts, R.S.; Miller, T.D.; Schaer, G.L.; Anderson, J.L.; Yusuf, S. The relationships of left ventricular ejection fraction, end-systolic volume index and infarct size to six-month mortality after hospital discharge following myocardial infarction treated by thrombolysis. J. Am. Coll. Cardiol. 2002, 39, 30-36. [CrossRef]

2. Lassen, J.F.; Botker, H.E.; Terkelsen, C.J. Timely and optimal treatment of patients with STEMI. Nat. Rev. Cardiol. 2013, 10, 41-48. [CrossRef] [PubMed]

3. Andersen, H.R.; Nielsen, T.T.; Rasmussen, K.; Thuesen, L.; Kelbaek, H.; Thayssen, P.; Abildgaard, U.; Pedersen, F.; Madsen, J.K.; Grande, P.; et al. A comparison of coronary angioplasty with fibrinolytic therapy in acute myocardial infarction. N. Engl. J. Med. 2003, 349, 733-742. [CrossRef] [PubMed]

4. Keeley, E.C.; Boura, J.A.; Grines, C.L. Primary angioplasty versus intravenous thrombolytic therapy for acute myocardial infarction: A quantitative review of 23 randomised trials. Lancet 2003, 361, 13-20. [CrossRef]

5. World Health Organisation. Available online: http://www.who.int/mediacentre/factsheets/fs317/en/ (accessed on 1 November 2018).

6. Yellon, D.M.; Hausenloy, D.J. Myocardial reperfusion injury. N. Engl. J. Med. 2007, 357, 1121-1135. [CrossRef]

7. Murry, C.E.; Jennings, R.B.; Reimer, K.A. Preconditioning with ischemia: A delay of lethal cell injury in ischemic myocardium. Circulation 1986, 74, 1124-1136. [CrossRef] [PubMed]

8. Kharbanda, R.K.; Mortensen, U.M.; White, P.A.; Kristiansen, S.B.; Schmidt, M.R.; Hoschtitzky, J.A.; Vogel, M.; Sorensen, K.; Redington, A.N.; MacAllister, R. Transient limb ischemia induces remote ischemic preconditioning in vivo. Circulation 2002, 106, 2881-2883. [CrossRef] [PubMed]

9. Przyklenk, K.; Bauer, B.; Ovize, M.; Kloner, R.A.; Whittaker, P. Regional ischemic 'preconditioning' protects remote virgin myocardium from subsequent sustained coronary occlusion. Circulation 1993, 87, 893-899. [CrossRef] [PubMed]

10. Botker, H.E.; Kharbanda, R.; Schmidt, M.R.; Bottcher, M.; Kaltoft, A.K.; Terkelsen, C.J.; Munk, K.; Andersen, N.H.; Hansen, T.M.; Trautner, S.; et al. Remote ischaemic conditioning before hospital admission, as a complement to angioplasty, and effect on myocardial salvage in patients with acute myocardial infarction: A randomised trial. Lancet 2010, 375, 727-734. [CrossRef] 
11. Cheung, M.M.; Kharbanda, R.K.; Konstantinov, I.E.; Shimizu, M.; Frndova, H.; Li, J.; Holtby, H.M.; Cox, P.N.; Smallhorn, J.F.; Van Arsdell, G.S.; et al. Randomized controlled trial of the effects of remote ischemic preconditioning on children undergoing cardiac surgery: First clinical application in humans. J. Am. Coll. Cardiol. 2006, 47, 2277-2282. [CrossRef] [PubMed]

12. Hausenloy, D.J.; Mwamure, P.K.; Venugopal, V.; Harris, J.; Barnard, M.; Grundy, E.; Ashley, E.; Vichare, S.; Di, S.C.; Kolvekar, S.; et al. Effect of remote ischaemic preconditioning on myocardial injury in patients undergoing coronary artery bypass graft surgery: A randomised controlled trial. Lancet 2007, 370, 575-579. [CrossRef]

13. Hougaard, K.D.; Hjort, N.; Zeidler, D.; Sorensen, L.; Norgaard, A.; Hansen, T.M.; von Weitzel-Mudersbach, P.; Simonsen, C.Z.; Damgaard, D.; Gottrup, H.; et al. Remote ischemic perconditioning as an adjunct therapy to thrombolysis in patients with acute ischemic stroke: A randomized trial. Stroke 2014, 45, 159-167. [CrossRef] [PubMed]

14. Zachara, N.E.; O’Donnell, N.; Cheung, W.D.; Mercer, J.J.; Marth, J.D.; Hart, G.W. Dynamic O-GlcNAc modification of nucleocytoplasmic proteins in response to stress. A survival response of mammalian cells. J. Biol. Chem. 2004, 279, 30133-30142. [CrossRef] [PubMed]

15. Zachara, N.E.; Hart, G.W. Cell signaling, the essential role of O-GlcNAc! Biochim. Biophys. Acta 2006, 1761, 599-617. [CrossRef] [PubMed]

16. Laczy, B.; Marsh, S.A.; Brocks, C.A.; Wittmann, I.; Chatham, J.C. Inhibition of O-GlcNAcase in perfused rat hearts by NAG-thiazolines at the time of reperfusion is cardioprotective in an O-GlcNAc-dependent manner. Am. J. Physiol. Heart Circ. Physiol. 2010, 299, H1715-H1727. [CrossRef] [PubMed]

17. Liu, J.; Pang, Y.; Chang, T.; Bounelis, P.; Chatham, J.C.; Marchase, R.B. Increased hexosamine biosynthesis and protein O-GlcNAc levels associated with myocardial protection against calcium paradox and ischemia. J. Mol. Cell. Cardiol. 2006, 40, 303-312. [CrossRef] [PubMed]

18. Liu, J.; Marchase, R.B.; Chatham, J.C. Glutamine-induced protection of isolated rat heart from ischemia/reperfusion injury is mediated via the hexosamine biosynthesis pathway and increased protein O-GlcNAc levels. J. Mol. Cell. Cardiol. 2007, 42, 177-185. [CrossRef] [PubMed]

19. Liu, J.; Marchase, R.B.; Chatham, J.C. Increased O-GlcNAc levels during reperfusion lead to improved functional recovery and reduced calpain proteolysis. Am. J. Physiol. Heart Circ. Physiol. 2007, 293, H1391-H1399. [CrossRef]

20. Jones, S.P.; Zachara, N.E.; Ngoh, G.A.; Hill, B.G.; Teshima, Y.; Bhatnagar, A.; Hart, G.W.; Marban, E. Cardioprotection by $\mathrm{N}$-acetylglucosamine linkage to cellular proteins. Circulation 2008, 117, 1172-1182. [CrossRef]

21. Paelestik, K.B.; Jespersen, N.R.; Jensen, R.V.; Johnsen, J.; Botker, H.E.; Kristiansen, S.B. Effects of hypoglycemia on myocardial susceptibility to ischemia-reperfusion injury and preconditioning in hearts from rats with and without type 2 diabetes. Cardiovasc. Diabetol. 2017, 16, 148. [CrossRef]

22. Vibjerg, J.R.; Johnsen, J.; Buus, K.S.; Zachara, N.E.; Botker, H.E. Ischemic preconditioning increases myocardial O-GlcNAc glycosylation. Scand. Cardiovasc. J. 2013, 47, 168-174.

23. Jensen, R.V.; Zachara, N.E.; Nielsen, P.H.; Kimose, H.H.; Kristiansen, S.B.; Botker, H.E. Impact of O-GlcNAc on cardioprotection by remote ischaemic preconditioning in non-diabetic and diabetic patients. Cardiovasc. Res. 2013, 97, 369-378. [CrossRef] [PubMed]

24. Champattanachai, V.; Marchase, R.B.; Chatham, J.C. Glucosamine protects neonatal cardiomyocytes from ischemia-reperfusion injury via increased protein-associated O-GlcNAc. Am. J. Physiol. Cell Physiol. 2007, 292, C178-C187. [CrossRef]

25. Champattanachai, V.; Marchase, R.B.; Chatham, J.C. Glucosamine protects neonatal cardiomyocytes from ischemia-reperfusion injury via increased protein O-GlcNAc and increased mitochondrial Bcl-2. Am. J. Physiol. Cell Physiol. 2008, 294, C1509-C1520. [CrossRef] [PubMed]

26. Ngoh, G.A.; Facundo, H.T.; Hamid, T.; Dillmann, W.; Zachara, N.E.; Jones, S.P. Unique hexosaminidase reduces metabolic survival signal and sensitizes cardiac myocytes to hypoxia/reoxygenation injury. Circ. Res. 2009, 104, 41-49. [CrossRef] [PubMed]

27. Zafir, A.; Readnower, R.; Long, B.W.; McCracken, J.; Aird, A.; Alvarez, A.; Cummins, T.D.; Li, Q.; Hill, B.G.; Bhatnagar, A.; et al. Protein O-GlcNAcylation is a novel cytoprotective signal in cardiac stem cells. Stem Cells 2013, 31, 765-775. [CrossRef] 
28. Ngoh, G.A.; Watson, L.J.; Facundo, H.T.; Dillmann, W.; Jones, S.P. Non-canonical glycosyltransferase modulates post-hypoxic cardiac myocyte death and mitochondrial permeability transition. J. Mol. Cell. Cardiol. 2008, 45, 313-325. [CrossRef]

29. Ngoh, G.A.; Hamid, T.; Prabhu, S.D.; Jones, S.P. O-GlcNAc signaling attenuates ER stress-induced cardiomyocyte death. Am. J. Physiol. Heart Circ. Physiol. 2009, 297, H1711-H1719. [CrossRef]

30. Milewski, S. Glucosamine-6-phosphate synthase-The multi-facets enzyme. Biochim. Biophys. Acta 2002, 1597, 173-192. [CrossRef]

31. Nagy, T.; Champattanachai, V.; Marchase, R.B.; Chatham, J.C. Glucosamine inhibits angiotensin II-induced cytoplasmic $\mathrm{Ca}^{2+}$ elevation in neonatal cardiomyocytes via protein-associated O-linked $\mathrm{N}$-acetylglucosamine. Am. J. Physiol. Cell Physiol. 2006, 290, C57-C65. [CrossRef]

32. Gloster, T.M.; Zandberg, W.F.; Heinonen, J.E.; Shen, D.L.; Deng, L.; Vocadlo, D.J. Hijacking a biosynthetic pathway yields a glycosyltransferase inhibitor within cells. Nat. Chem. Biol. 2011, 7, 174-181. [CrossRef] [PubMed]

33. Lee, T.N.; Alborn, W.E.; Knierman, M.D.; Konrad, R.J. Alloxan is an inhibitor of O-GlcNAc-selective $N$-acetyl- $\beta$-D-glucosaminidase. Biochem. Biophys. Res. Commun. 2006, 350, 1038-1043. [CrossRef] [PubMed]

34. Slawson, C.; Zachara, N.E.; Vosseller, K.; Cheung, W.D.; Lane, M.D.; Hart, G.W. Perturbations in O-linked $\beta-N$-acetylglucosamine protein modification cause severe defects in mitotic progression and cytokinesis. J. Biol. Chem. 2005, 280, 32944-32956. [CrossRef] [PubMed]

35. Han, I.; Kudlow, J.E. Reduced O glycosylation of Sp1 is associated with increased proteasome susceptibility. Mol. Cell. Biol. 1997, 17, 2550-2558. [CrossRef] [PubMed]

36. Jackson, S.P.; Tjian, R. O-glycosylation of eukaryotic transcription factors: Implications for mechanisms of transcriptional regulation. Cell 1988, 55, 125-133. [CrossRef]

37. Vosseller, K.; Sakabe, K.; Wells, L.; Hart, G.W. Diverse regulation of protein function by O-GlcNAc: A nuclear and cytoplasmic carbohydrate post-translational modification. Curr. Opin. Chem. Biol. 2002, 6, 851-857. [CrossRef]

38. Zhu, Y.; Shan, X.; Yuzwa, S.A.; Vocadlo, D.J. The emerging link between O-GlcNAc and Alzheimer disease. J. Biol. Chem. 2014, 289, 34472-34481. [CrossRef]

39. Mazars, R.; Gonzalez-de-Peredo, A.; Cayrol, C.; Lavigne, A.C.; Vogel, J.L.; Ortega, N.; Lacroix, C.; Gautier, V.; Huet, G.; Ray, A.; et al. The THAP-zinc finger protein THAP1 associates with coactivator HCF-1 and O-GlcNAc transferase: A link between DYT6 and DYT3 dystonias. J. Biol. Chem. 2010, 285, 13364-13371. [CrossRef]

40. Slawson, C.; Hart, G.W. O-GlcNAc signalling: Implications for cancer cell biology. Nat. Rev. Cancer 2011, 11, 678-684. [CrossRef]

41. Lunde, I.G.; Aronsen, J.M.; Kvaloy, H.; Qvigstad, E.; Sjaastad, I.; Tonnessen, T.; Christensen, G.; Gronning-Wang, L.M.; Carlson, C.R. Cardiac O-GlcNAc signaling is increased in hypertrophy and heart failure. Physiol. Genom. 2012, 44, 162-172. [CrossRef]

42. Marshall, S.; Bacote, V.; Traxinger, R.R. Discovery of a metabolic pathway mediating glucose-induced desensitization of the glucose transport system. Role of hexosamine biosynthesis in the induction of insulin resistance. J. Biol. Chem. 1991, 266, 4706-4712. [PubMed]

43. McClain, D.A.; Paterson, A.J.; Roos, M.D.; Wei, X.; Kudlow, J.E. Glucose and glucosamine regulate growth factor gene expression in vascular smooth muscle cells. Proc. Natl. Acad. Sci. USA 1992, 89, 8150-8154. [CrossRef] [PubMed]

44. Fulop, N.; Mason, M.M.; Dutta, K.; Wang, P.; Davidoff, A.J.; Marchase, R.B.; Chatham, J.C. Impact of Type 2 diabetes and aging on cardiomyocyte function and O-linked $\mathrm{N}$-acetylglucosamine levels in the heart. Am. J. Physiol. Cell Physiol. 2007, 292, C1370-C1378. [CrossRef] [PubMed]

45. Hwang, S.Y.; Shin, J.H.; Hwang, J.S.; Kim, S.Y.; Shin, J.A.; Oh, E.S.; Oh, S.; Kim, J.B.; Lee, J.K.; Han, I.O. Glucosamine exerts a neuroprotective effect via suppression of inflammation in rat brain ischemia/reperfusion injury. Glia 2010, 58, 1881-1892. [CrossRef] [PubMed]

46. Kawabata, K.I.; Netticadan, T.; Osada, M.; Tamura, K.; Dhalla, N.S. Mechanisms of ischemic preconditioning effects on $\mathrm{Ca}(2+)$ paradox-induced changes in heart. Am. J. Physiol. Heart Circ. Physiol. 2000, 278, H1008-H1015. [CrossRef] [PubMed] 
47. Temsah, R.M.; Kawabata, K.; Chapman, D.; Dhalla, N.S. Preconditioning prevents alterations in cardiac SR gene expression due to ischemia-reperfusion. Am. J. Physiol. Heart Circ. Physiol. 2002, 282, H1461-H1466. [CrossRef]

48. Zimmerman, A.N.; Hulsmann, W.C. Paradoxical influence of calcium ions on the permeability of the cell membranes of the isolated rat heart. Nature 1966, 211, 646-647. [CrossRef] [PubMed]

49. Hulsmann, W.C. Morphological changes of heart muscle caused by successive perfusion with calcium-free and calcium-containing solutions (calcium paradox). Cardiovasc. Res. 2000, 45, 119-120, 122. [CrossRef]

50. Ngoh, G.A.; Watson, L.J.; Facundo, H.T.; Jones, S.P. Augmented O-GlcNAc signaling attenuates oxidative stress and calcium overload in cardiomyocytes. Amino Acids 2011, 40, 895-911. [CrossRef] [PubMed]

51. Rengifo, J.; Gibson, C.J.; Winkler, E.; Collin, T.; Ehrlich, B.E. Regulation of the inositol 1,4,5-trisphosphate receptor type I by O-GlcNAc glycosylation. J. Neurosci. 2007, 27, 13813-13821. [CrossRef]

52. Cho, H.J.; Mook-Jung, I. O-GlcNAcylation regulates endoplasmic reticulum exit sites through Sec31A modification in conventional secretory pathway. FASEB J. 2018, 32, 4641-4657. [CrossRef] [PubMed]

53. Baines, C.P. The mitochondrial permeability transition pore and ischemia-reperfusion injury. Basic Res. Cardiol. 2009, 104, 181-188. [CrossRef] [PubMed]

54. Halestrap, A.P. A pore way to die: The role of mitochondria in reperfusion injury and cardioprotection. Biochem. Soc. Trans. 2010, 38, 841-860. [CrossRef]

55. Hausenloy, D.J.; Yellon, D.M. The mitochondrial permeability transition pore: Its fundamental role in mediating cell death during ischaemia and reperfusion. J. Mol. Cell. Cardiol. 2003, 35, 339-341. [CrossRef]

56. Goldberg, H.; Whiteside, C.; Fantus, I.G. O-linked $\beta$-N-acetylglucosamine supports p38 MAPK activation by high glucose in glomerular mesangial cells. Am. J. Physiol. Endocrinol. Metab. 2011, 301, E713-E726. [CrossRef] [PubMed]

57. Brownlee, M. Biochemistry and molecular cell biology of diabetic complications. Nature 2001, 414, 813-820. [CrossRef] [PubMed]

58. Lima, V.V.; Spitler, K.; Choi, H.; Webb, R.C.; Tostes, R.C. O-GlcNAcylation and oxidation of proteins: Is signalling in the cardiovascular system becoming sweeter? Clin. Sci. 2012, 123, 473-486. [CrossRef]

59. Singh, L.P.; Cheng, D.W.; Kowluru, R.; Levi, E.; Jiang, Y. Hexosamine induction of oxidative stress, hypertrophy and laminin expression in renal mesangial cells: Effect of the anti-oxidant $\alpha$-lipoic acid. Cell Biochem. Funct. 2007, 25, 537-550. [CrossRef] [PubMed]

60. Hirose, K.; Tsutsumi, Y.M.; Tsutsumi, R.; Shono, M.; Katayama, E.; Kinoshita, M.; Tanaka, K.; Oshita, S. Role of the O-linked $\beta-N$-acetylglucosamine in the cardioprotection induced by isoflurane. Anesthesiology 2011, 115, 955-962. [CrossRef]

61. Miura, T.; Tanno, M. The mPTP and its regulatory proteins: Final common targets of signalling pathways for protection against necrosis. Cardiovasc. Res. 2012, 94, 181-189. [CrossRef]

62. Woodfield, K.; Ruck, A.; Brdiczka, D.; Halestrap, A.P. Direct demonstration of a specific interaction between cyclophilin-D and the adenine nucleotide translocase confirms their role in the mitochondrial permeability transition. Biochem. J. 1998, 336 Pt 2, 287-290. [CrossRef]

63. Qi, X.; Vallentin, A.; Churchill, E.; Mochly-Rosen, D. deltaPKC participates in the endoplasmic reticulum stress-induced response in cultured cardiac myocytes and ischemic heart. J. Mol. Cell. Cardiol. 2007, 43, 420-428. [CrossRef]

64. Teshima, Y.; Akao, M.; Jones, S.P.; Marban, E. Uncoupling protein-2 overexpression inhibits mitochondrial death pathway in cardiomyocytes. Circ. Res. 2003, 93, 192-200. [CrossRef]

65. Kim, I.; Xu, W.; Reed, J.C. Cell death and endoplasmic reticulum stress: Disease relevance and therapeutic opportunities. Nat. Rev. Drug Discov. 2008, 7, 1013-1030. [CrossRef]

66. Oyadomari, S.; Mori, M. Roles of CHOP/GADD153 in endoplasmic reticulum stress. Cell Death Differ. 2004, 11, 381-389. [CrossRef]

67. Nishitoh, H. CHOP is a multifunctional transcription factor in the ER stress response. J. Biochem. 2012, 151, 217-219. [CrossRef]

68. Tabas, I.; Ron, D. Integrating the mechanisms of apoptosis induced by endoplasmic reticulum stress. Nat. Cell Biol. 2011, 13, 184-190. [CrossRef]

69. Suh, H.N.; Lee, Y.J.; Kim, M.O.; Ryu, J.M.; Han, H.J. Glucosamine-induced Sp1 O-GlcNAcylation ameliorates hypoxia-induced SGLT dysfunction in primary cultured renal proximal tubule cells. J. Cell. Physiol. 2014, 229, 1557-1568. [CrossRef] 
70. Jang, I.; Kim, H.B.; Seo, H.; Kim, J.Y.; Choi, H.; Yoo, J.S.; Kim, J.W.; Cho, J.W. O-GlcNAcylation of eIF2 $\alpha$ regulates the phospho-eIF2 $\alpha$-mediated ER stress response. Biochim. Biophys. Acta 2015, 1853, 1860-1869. [CrossRef]

71. Vinten-Johansen, J. Involvement of neutrophils in the pathogenesis of lethal myocardial reperfusion injury. Cardiovasc. Res. 2004, 61, 481-497. [CrossRef]

72. Cooper, M.; Lindholm, P.; Pieper, G.; Seibel, R.; Moore, G.; Nakanishi, A.; Dembny, K.; Komorowski, R.; Johnson, C.; Adams, M.; et al. Myocardial nuclear factor- $\mathrm{kB}$ activity and nitric oxide production in rejecting cardiac allografts. Transplantation 1998, 66, 838-844. [CrossRef]

73. Sawa, Y.; Morishita, R.; Suzuki, K.; Kagisaki, K.; Kaneda, Y.; Maeda, K.; Kadoba, K.; Matsuda, H. A novel strategy for myocardial protection using in vivo transfection of cis element 'decoy' against NFKB binding site: Evidence for a role of NFKB in ischemia-reperfusion injury. Circulation 1997, 96, II-4.

74. Xuan, Y.T.; Tang, X.L.; Banerjee, S.; Takano, H.; Li, R.C.; Han, H.; Qiu, Y.; Li, J.J.; Bolli, R. Nuclear factor-kB plays an essential role in the late phase of ischemic preconditioning in conscious rabbits. Circ. Res. 1999, 84, 1095-1109. [CrossRef]

75. Morgan, E.N.; Boyle, E.M., Jr.; Yun, W.; Griscavage-Ennis, J.M.; Farr, A.L.; Canty, T.G., Jr.; Pohlman, T.H.; Verrier, E.D. An essential role for NF-kB in the cardioadaptive response to ischemia. Ann. Thorac. Surg. 1999, 68, 377-382. [CrossRef]

76. Shen, Y.; Qiu, T.; Liu, X.H.; Zhang, L.; Wang, Z.S.; Zhou, J.Q. Renal ischemia-reperfusion injury attenuated by splenic ischemic preconditioning. Eur. Rev. Med. Pharmacol. Sci. 2018, 22, 2134-2142.

77. Xiao, Q.; Ye, Q.; Wang, W.; Xiao, J.; Fu, B.; Xia, Z.; Zhang, X.; Liu, Z.; Zeng, X. Mild hypothermia pretreatment protects against liver ischemia reperfusion injury via the PI3K/AKT/FOXO3a pathway. Mol. Med. Rep. 2017, 16, 7520-7526. [CrossRef]

78. Ji, Y.Y.; Wang, Z.D.; Wang, S.F.; Wang, B.T.; Yang, Z.A.; Zhou, X.R.; Lei, N.N.; Yue, W.N. Ischemic preconditioning ameliorates intestinal injury induced by ischemia-reperfusion in rats. World J. Gastroenterol. 2015, 21, 8081-8088. [CrossRef]

79. Gouze, J.N.; Bianchi, A.; Becuwe, P.; Dauca, M.; Netter, P.; Magdalou, J.; Terlain, B.; Bordji, K. Glucosamine modulates IL-1-induced activation of rat chondrocytes at a receptor level, and by inhibiting the NF- $\mathrm{K} B$ pathway. FEBS Lett. 2002, 510, 166-170. [CrossRef]

80. Hua, J.; Sakamoto, K.; Nagaoka, I. Inhibitory actions of glucosamine, a therapeutic agent for osteoarthritis, on the functions of neutrophils. J. Leukoc. Biol. 2002, 71, 632-640.

81. Ma, L.; Rudert, W.A.; Harnaha, J.; Wright, M.; Machen, J.; Lakomy, R.; Qian, S.; Lu, L.; Robbins, P.D.; Trucco, M.; et al. Immunosuppressive effects of glucosamine. J. Biol. Chem. 2002, 277, 39343-39349. [CrossRef]

82. Zhang, G.X.; Yu, S.; Gran, B.; Rostami, A. Glucosamine abrogates the acute phase of experimental autoimmune encephalomyelitis by induction of Th2 response. J. Immunol. 2005, 175, 7202-7208. [CrossRef]

83. Xing, D.; Feng, W.; Not, L.G.; Miller, A.P.; Zhang, Y.; Chen, Y.F.; Majid-Hassan, E.; Chatham, J.C.; Oparil, S. Increased protein O-GlcNAc modification inhibits inflammatory and neointimal responses to acute endoluminal arterial injury. Am. J. Physiol. Heart Circ. Physiol. 2008, 295, H335-H342. [CrossRef]

84. He, Y.; Ma, X.; Li, D.; Hao, J. Thiamet G mediates neuroprotection in experimental stroke by modulating microglia/macrophage polarization and inhibiting NF-кB p65 signaling. J. Cereb. Blood Flow Metab. 2017, 37, 2938-2951. [CrossRef]

85. Yang, S.; Zou, L.Y.; Bounelis, P.; Chaudry, I.; Chatham, J.C.; Marchase, R.B. Glucosamine administration during resuscitation improves organ function after trauma hemorrhage. Shock 2006, 25, 600-607. [CrossRef]

86. Zou, L.; Yang, S.; Hu, S.; Chaudry, I.H.; Marchase, R.B.; Chatham, J.C. The protective effects of PUGNAc on cardiac function after trauma-hemorrhage are mediated via increased protein O-GlcNAc levels. Shock 2007, 27, 402-408. [CrossRef]

87. Not, L.G.; Brocks, C.A.; Vamhidy, L.; Marchase, R.B.; Chatham, J.C. Increased O-linked $\beta-N$-acetylglucosamine levels on proteins improves survival, reduces inflammation and organ damage $24 \mathrm{~h}$ after trauma-hemorrhage in rats. Crit. Care Med. 2010, 38, 562-571. [CrossRef]

88. Not, L.G.; Marchase, R.B.; Fulop, N.; Brocks, C.A.; Chatham, J.C. Glucosamine administration improves survival rate after severe hemorrhagic shock combined with trauma in rats. Shock 2007, 28, 345-352. 
89. Zou, L.; Yang, S.; Champattanachai, V.; Hu, S.; Chaudry, I.H.; Marchase, R.B.; Chatham, J.C. Glucosamine improves cardiac function following trauma-hemorrhage by increased protein O-GlcNAcylation and attenuation of NF-kB signaling. Am. J. Physiol. Heart Circ. Physiol. 2009, 296, H515-H523. [CrossRef]

90. Zhang, F.; Su, K.; Yang, X.; Bowe, D.B.; Paterson, A.J.; Kudlow, J.E. O-GlcNAc modification is an endogenous inhibitor of the proteasome. Cell 2003, 115, 715-725. [CrossRef]

91. Ju, Y.; Hua, J.; Sakamoto, K.; Ogawa, H.; Nagaoka, I. Modulation of TNF- $\alpha$-induced endothelial cell activation by glucosamine, a naturally occurring amino monosaccharide. Int. J. Mol. Med. 2008, 22, 809-815.

92. Xing, D.; Gong, K.; Feng, W.; Nozell, S.E.; Chen, Y.F.; Chatham, J.C.; Oparil, S. O-GlcNAc modification of NFKB p65 inhibits TNF- $\alpha$-induced inflammatory mediator expression in rat aortic smooth muscle cells. PLOS ONE 2011, 6, e24021. [CrossRef]

93. Hilgers, R.H.; Xing, D.; Gong, K.; Chen, Y.F.; Chatham, J.C.; Oparil, S. Acute O-GlcNAcylation prevents inflammation-induced vascular dysfunction. Am. J. Physiol. Heart Circ. Physiol. 2012, 303, H513-H522. [CrossRef]

94. Whitley, D.; Goldberg, S.P.; Jordan, W.D. Heat shock proteins: A review of the molecular chaperones. J. Vasc. Surg. 1999, 29, 748-751. [CrossRef]

95. Sohn, K.C.; Lee, K.Y.; Park, J.E.; Do, S.I. OGT functions as a catalytic chaperone under heat stress response: A unique defense role of OGT in hyperthermia. Biochem. Biophys. Res. Commun. 2004, 322, 1045-1051. [CrossRef]

96. Kazemi, Z.; Chang, H.; Haserodt, S.; McKen, C.; Zachara, N.E. O-linked $\beta$-N-acetylglucosamine (O-GlcNAc) regulates stress-induced heat shock protein expression in a GSK-3 $\beta$-dependent manner. J. Biol. Chem. 2010, 285, 39096-39107. [CrossRef]

97. Tanimoto, T.; Parseghian, M.H.; Nakahara, T.; Kawai, H.; Narula, N.; Kim, D.; Nishimura, R.; Weisbart, R.H.; Chan, G.; Richieri, R.A.; et al. Cardioprotective Effects of HSP72 Administration on Ischemia-Reperfusion Injury. J. Am. Coll. Cardiol. 2017, 70, 1479-1492. [CrossRef]

98. Song, Y.J.; Zhong, C.B.; Wang, X.B. Heat shock protein 70: A promising therapeutic target for myocardial ischemia-reperfusion injury. J. Cell. Physiol. 2018, 23, 1190-1207. [CrossRef]

99. Liu, X.; Zhang, C.; Zhang, C.; Li, J.; Guo, W.; Yan, D.; Yang, C.; Zhao, J.; Xia, T.; Wang, Y.; et al. Heat shock protein 70 inhibits cardiomyocyte necroptosis through repressing autophagy in myocardial ischemia/reperfusion injury. In Vitro Cell. Dev. Biol. Anim. 2016, 52, 690-698. [CrossRef]

100. Konstantinov, I.E.; Arab, S.; Kharbanda, R.K.; Li, J.; Cheung, M.M.; Cherepanov, V.; Downey, G.P.; Liu, P.P.; Cukerman, E.; Coles, J.G.; et al. The remote ischemic preconditioning stimulus modifies inflammatory gene expression in humans. Physiol. Genom. 2004, 19, 143-150. [CrossRef]

101. Wischmeyer, P.E.; Jayakar, D.; Williams, U.; Singleton, K.D.; Riehm, J.; Bacha, E.A.; Jeevanandam, V.; Christians, U.; Serkova, N. Single dose of glutamine enhances myocardial tissue metabolism, glutathione content, and improves myocardial function after ischemia-reperfusion injury. JPEN J. Parenter. Enter. Nutr. 2003, 27, 396-403. [CrossRef]

102. Guinez, C.; Lemoine, J.; Michalski, J.C.; Lefebvre, T. 70-kDa-heat shock protein presents an adjustable lectinic activity towards O-linked N-acetylglucosamine. Biochem. Biophys. Res. Commun. 2004, 319, 21-26. [CrossRef]

103. Hausenloy, D.J.; Tsang, A.; Mocanu, M.M.; Yellon, D.M. Ischemic preconditioning protects by activating prosurvival kinases at reperfusion. Am. J. Physiol. Heart Circ. Physiol. 2005, 288, H971-H976. [CrossRef]

104. Hausenloy, D.J.; Mocanu, M.M.; Yellon, D.M. Cross-talk between the survival kinases during early reperfusion: Its contribution to ischemic preconditioning. Cardiovasc. Res. 2004, 63, 305-312. [CrossRef]

105. Wang, S.; Huang, X.; Sun, D.; Xin, X.; Pan, Q.; Peng, S.; Liang, Z.; Luo, C.; Yang, Y.; Jiang, H.; et al. Extensive crosstalk between O-GlcNAcylation and phosphorylation regulates Akt signaling. PLoS ONE 2012, 7, e37427. [CrossRef]

106. Vosseller, K.; Wells, L.; Lane, M.D.; Hart, G.W. Elevated nucleocytoplasmic glycosylation by O-GlcNAc results in insulin resistance associated with defects in Akt activation in 3T3-L1 adipocytes. Proc. Natl. Acad. Sci. USA 2002, 99, 5313-5318. [CrossRef]

107. Kang, E.S.; Han, D.; Park, J.; Kwak, T.K.; Oh, M.A.; Lee, S.A.; Choi, S.; Park, Z.Y.; Kim, Y.; Lee, J.W. O-GlcNAc modulation at Akt1 Ser473 correlates with apoptosis of murine pancreatic $\beta$ cells. Exp. Cell Res. 2008, 314, 2238-2248. [CrossRef]

108. Shi, J.; Gu, J.H.; Dai, C.L.; Gu, J.; Jin, X.; Sun, J.; Iqbal, K.; Liu, F.; Gong, C.X. O-GlcNAcylation regulates ischemia-induced neuronal apoptosis through AKT signaling. Sci. Rep. 2015, 5, 14500. [CrossRef] 
109. Hu, J.; Chen, R.; Jia, P.; Fang, Y.; Liu, T.; Song, N.; Xu, X.; Ji, J.; Ding, X. Augmented O-GlcNAc signaling via glucosamine attenuates oxidative stress and apoptosis following contrast-induced acute kidney injury in rats. Free Radic. Biol. Med. 2017, 103, 121-132. [CrossRef]

110. Ku, N.O.; Toivola, D.M.; Strnad, P.; Omary, M.B. Cytoskeletal keratin glycosylation protects epithelial tissue from injury. Nat. Cell Biol. 2010, 12, 876-885. [CrossRef]

111. Lecour, S. Multiple protective pathways against reperfusion injury: A SAFE path without Aktion? J. Mol. Cell. Cardiol. 2009, 46, 607-609. [CrossRef]

112. Smith, R.M.; Suleman, N.; McCarthy, J.; Sack, M.N. Classic ischemic but not pharmacologic preconditioning is abrogated following genetic ablation of the TNF $\alpha$ gene. Cardiovasc. Res. 2002, 55, 553-560. [CrossRef]

113. Lambert, M.; Bastide, B.; Cieniewski-Bernard, C. Involvement of O-GlcNAcylation in the Skeletal Muscle Physiology and Physiopathology: Focus on Muscle Metabolism. Front. Endocrinol. 2018, 9, 578. [CrossRef]

114. Darley-Usmar, V.M.; Ball, L.E.; Chatham, J.C. Protein O-linked $\beta$-N-acetylglucosamine: A novel effector of cardiomyocyte metabolism and function. J. Mol. Cell. Cardiol. 2012, 52, 538-549. [CrossRef]

115. Ma, J.; Hart, G.W. Protein O-GlcNAcylation in diabetes and diabetic complications. Expert Rev. Proteom. 2013, 10, 365-380. [CrossRef]

116. Lima, V.V.; Giachini, F.R.; Carneiro, F.S.; Carneiro, Z.N.; Fortes, Z.B.; Carvalho, M.H.; Webb, R.C.; Tostes, R.C. Increased vascular O-GlcNAcylation augments reactivity to constrictor stimuli-VASOACTIVE PEPTIDE SYMPOSIUM. J. Am. Soc. Hypertens. 2008, 2, 410-417. [CrossRef]

117. Degrell, P.; Cseh, J.; Mohas, M.; Molnar, G.A.; Pajor, L.; Chatham, J.C.; Fulop, N.; Wittmann, I. Evidence of O-linked N-acetylglucosamine in diabetic nephropathy. Life Sci. 2009, 84, 389-393. [CrossRef]

118. Akimoto, Y.; Kreppel, L.K.; Hirano, H.; Hart, G.W. Increased O-GlcNAc transferase in pancreas of rats with streptozotocin-induced diabetes. Diabetologia 2000, 43, 1239-1247. [CrossRef]

119. Wang, Z.; Park, K.; Comer, F.; Hsieh-Wilson, L.C.; Saudek, C.D.; Hart, G.W. Site-specific GlcNAcylation of human erythrocyte proteins: Potential biomarker(s) for diabetes. Diabetes 2009, 58, 309-317. [CrossRef]

120. Akimoto, Y.; Kawakami, H.; Yamamoto, K.; Munetomo, E.; Hida, T.; Hirano, H. Elevated expression of O-GlcNAc-modified proteins and O-GlcNAc transferase in corneas of diabetic Goto-Kakizaki rats. Investig. Ophthalmol. Vis. Sci. 2003, 44, 3802-3809. [CrossRef]

121. Liu, Y.; Thornton, J.D.; Cohen, M.V.; Downey, J.M.; Schaffer, S.W. Streptozotocin-induced non-insulin-dependent diabetes protects the heart from infarction. Circulation 1993, 88, 1273-1278. [CrossRef]

122. Povlsen, J.A.; Lofgren, B.; Dalgas, C.; Birkler, R.I.; Johannsen, M.; Stottrup, N.B.; Botker, H.E. Protection against myocardial ischemia-reperfusion injury at onset of type 2 diabetes in Zucker diabetic fatty rats is associated with altered glucose oxidation. PLoS ONE 2013, 8, e64093. [CrossRef]

123. Galagudza, M.M.; Nekrasova, M.K.; Syrenskii, A.V.; Nifontov, E.M. Resistance of the myocardium to ischemia and the efficacy of ischemic preconditioning in experimental diabetes mellitus. Neurosci. Behav. Physiol. 2007, 37, 489-493. [CrossRef]

124. Kristiansen, S.B.; Lofgren, B.; Stottrup, N.B.; Khatir, D.; Nielsen-Kudsk, J.E.; Nielsen, T.T.; Botker, H.E.; Flyvbjerg, A. Ischaemic preconditioning does not protect the heart in obese and lean animal models of type 2 diabetes. Diabetologia 2004, 47, 1716-1721. [CrossRef]

125. Tsang, A.; Hausenloy, D.J.; Mocanu, M.M.; Carr, R.D.; Yellon, D.M. Preconditioning the diabetic heart: The importance of Akt phosphorylation. Diabetes 2005, 54, 2360-2364. [CrossRef]

126. Hjortbak, M.V.; Hjort, J.; Povlsen, J.A.; Jensen, R.V.; Stottrup, N.B.; Laursen, M.R.; Jespersen, N.R.; Lofgren, B.; Botker, H.E. Influence of diabetes mellitus duration on the efficacy of ischemic preconditioning in a Zucker diabetic fatty rat model. PLoS ONE 2018, 13, e0192981. [CrossRef]

127. Kristensen, J.; Maeng, M.; Mortensen, U.M.; Berg, J.; Rehling, M.; Nielsen, T.T. Lack of cardioprotection from metabolic support with glutamine or glutamate in a porcine coronary occlusion model. Scand. Cardiovasc. J. 2005, 39, 115-120. [CrossRef]

128. Aghazadeh-Habashi, A.; Jamali, F. The glucosamine controversy; a pharmacokinetic issue. J. Pharm. Pharm. Sci. 2011, 14, 264-273. [CrossRef]

129. Solskov, L.; Lofgren, B.; Kristiansen, S.B.; Jessen, N.; Pold, R.; Nielsen, T.T.; Botker, H.E.; Schmitz, O.; Lund, S. Metformin induces cardioprotection against ischaemia/reperfusion injury in the rat heart $24 \mathrm{~h}$ after administration. Basic Clin. Pharmacol. Toxicol. 2008, 103, 82-87. [CrossRef] 
130. Kim, Y.S.; Kim, M.; Choi, M.Y.; Lee, D.H.; Roh, G.S.; Kim, H.J.; Kang, S.S.; Cho, G.J.; Kim, S.J.; Yoo, J.M.; et al. Metformin protects against retinal cell death in diabetic mice. Biochem. Biophys. Res. Commun. 2017, 492, 397-403. [CrossRef]

131. Ellenberger, C.; Sologashvili, T.; Kreienbuhl, L.; Cikirikcioglu, M.; Diaper, J.; Licker, M. Myocardial Protection by Glucose-Insulin-Potassium in Moderate- to High-Risk Patients Undergoing Elective On-Pump Cardiac Surgery: A Randomized Controlled Trial. Anesth. Analg. 2018, 126, 1133-1141. [CrossRef]

132. Ahmad, S.; Ahmad, R.A.; Qureshi, B.A.; Baig, M.A.R. Myocardial protection with Glucose-Insulin-Potassium infusion during adult cardiac surgery. Pak. J. Med. Sci. 2017, 33, 325-329. [CrossRef]

133. Selker, H.P.; Udelson, J.E.; Massaro, J.M.; Ruthazer, R.; D'Agostino, R.B.; Griffith, J.L.; Sheehan, P.R.; Desvigne-Nickens, P.; Rosenberg, Y.; Tian, X.; et al. One-year outcomes of out-of-hospital administration of intravenous glucose, insulin, and potassium (GIK) in patients with suspected acute coronary syndromes (from the IMMEDIATE [Immediate Myocardial Metabolic Enhancement During Initial Assessment and Treatment in Emergency Care] Trial). Am. J. Cardiol. 2014, 113, 1599-1605.

134. Yang, Y.M.; Zhu, J.; Tan, H.Q.; Liang, Y.; Zhang, Y.; Li, Y.; Li, J.D.; Liu, L.S. [Effect of high dose glucose-insulin-potassium infusion in patients with acute ST-segment elevation myocardial infarction: Analysis of 7510 patients in China as part of CREATE-ECLA study]. Zhonghua Yi Xue Za Zhi 2008, 88, 1806-1810.

135. Diaz, R.; Goyal, A.; Mehta, S.R.; Afzal, R.; Xavier, D.; Pais, P.; Chrolavicius, S.; Zhu, J.; Kazmi, K.; Liu, L.; et al. Glucose-insulin-potassium therapy in patients with ST-segment elevation myocardial infarction. JAMA 2007, 298, 2399-2405. [CrossRef]

136. Rasoul, S.; Ottervanger, J.P.; Timmer, J.R.; Svilaas, T.; Henriques, J.P.; Dambrink, J.H.; van der Horst, I.C.; Zijlstra, F. One year outcomes after glucose-insulin-potassium in ST elevation myocardial infarction. The Glucose-insulin-potassium study II. Int. J. Cardiol. 2007, 122, 52-55. [CrossRef]

137. Howell, N.J.; Ashrafian, H.; Drury, N.E.; Ranasinghe, A.M.; Contractor, H.; Isackson, H.; Calvert, M.; Williams, L.K.; Freemantle, N.; Quinn, D.W.; et al. Glucose-insulin-potassium reduces the incidence of low cardiac output episodes after aortic valve replacement for aortic stenosis in patients with left ventricular hypertrophy: Results from the Hypertrophy, Insulin, Glucose, and Electrolytes (HINGE) trial. Circulation 2011, 123, 170-177. [CrossRef]

138. Chun, W.J.; Nah, D.Y.; Bae, J.H.; Chung, J.W.; Lee, H.; Moon, I.S. Glucose-insulin-potassium solution protects ventricular myocytes of neonatal rat in an in vitro coverslip ischemia/reperfusion model. Korean Circ. J. 2015, 45, 234-241. [CrossRef]

139. Sack, M.N.; Yellon, D.M. Insulin therapy as an adjunct to reperfusion after acute coronary ischemia: A proposed direct myocardial cell survival effect independent of metabolic modulation. J. Am. Coll. Cardiol. 2003, 41, 1404-1407. [CrossRef]

140. Jonassen, A.K.; Sack, M.N.; Mjos, O.D.; Yellon, D.M. Myocardial protection by insulin at reperfusion requires early administration and is mediated via Akt and p70s6 kinase cell-survival signaling. Circ. Res. 2001, 89, 1191-1198. [CrossRef]

141. Julier, K.; da Silva, R.; Garcia, C.; Bestmann, L.; Frascarolo, P.; Zollinger, A.; Chassot, P.G.; Schmid, E.R.; Turina, M.I.; von Segesser, L.K.; et al. Preconditioning by sevoflurane decreases biochemical markers for myocardial and renal dysfunction in coronary artery bypass graft surgery: A double-blinded, placebo-controlled, multicenter study. Anesthesiology 2003, 98, 1315-1327. [CrossRef]

142. Landoni, G.; Fochi, O.; Torri, G. Cardiac protection by volatile anaesthetics: A review. Curr. Vasc. Pharmacol. 2008, 6, 108-111. [CrossRef]

143. Belhomme, D.; Peynet, J.; Louzy, M.; Launay, J.M.; Kitakaze, M.; Menasche, P. Evidence for preconditioning by isoflurane in coronary artery bypass graft surgery. Circulation 1999, 100, II340-II344. [CrossRef]

(C) 2019 by the authors. Licensee MDPI, Basel, Switzerland. This article is an open access article distributed under the terms and conditions of the Creative Commons Attribution (CC BY) license (http://creativecommons.org/licenses/by/4.0/). 